\title{
How can we manage urinary incontinence following radical colpectomy? Literature review apropos of a rare entity
}

\author{
Tanja Huelder* and Rene Hornung \\ Department of Obstetrics and Gynecology, Cantonal Hospital St. Gallen, Switzerland
}

\begin{abstract}
Urinary incontinence following radical oncologic colpectomy is a rare condition with severe reduction of quality of life. A systematic review of the literature was performed to find the optimal incontinence therapy for these patients. The database search revealed no systematic therapeutic concept. We present a case of a postmenopausal, hysterectomized virgin who underwent radical laparoscopic colpectomy for vaginal melanoma with consecutive de novo predominant stress urinary incontinence. Transurethral submucosal injection of the bulking agent polyacrylamide-hydrogel resulted in a substantial relief of discomfort. In combination with the serotonin-norepinephrine reuptake inhibitor duloxetine the patient was fully satisfied. As demonstrated by this case minimally invasive treatment of postoperative urinary incontinence after colpectomy seems to be a valuable therapeutic option to allow a fast relief of urinary incontinence symptoms and discomfort.
\end{abstract}

\section{Introduction}

We were confronted with a woman who underwent oncological total colpectomy for vaginal melanoma. After oncological surgery she complained about de novo urinary incontinence. Urinary incontinence is a common disorder among gynecological patients and there is a wide variety of treatment options. The established therapy of Stress Urinary Incontinence (SUI) used to be colposuspension. During the last decade, this operation has mostly been replaced by midurethral sling operations. In addition, the injection of periurethral bulking agents is used to treat comorbid patients who are not eligible for surgery. Nonsurgical treatments consist in local estrogen therapy, physiotherapy (pelvic floor exercise and/or electrical stimulation as well as the use of pessaries) and the use of the Serotonin-Norepinephrine Reuptake Inhibitor (SNRI) duloxetine.

Radical colpectomy for oncologic reasons removes the vaginal and in part vulvar tissue including those structures suspending the urethra and the urinary bladder. This results in a severe urinary incontinence. Unfortunately, there is very little published expertise on how to treat these patients. Therefore, the PubMed databank was searched for this topic.

\section{Review}

\section{Material and methods}

The PubMed databank was searched for the keywords (colpectomy OR vaginectomy OR colpocleisis) AND (urinary incontinence) regardless the date or language of publication. This search revealed 52 hits. No reports were found for keywords (colpocleisis OR colpectomy) AND (bulking agent).

\section{Results}

10 out of 52 reports about the combination of keywords (colpectomy OR vaginectomy OR colpocleisis) AND (urinary incontinence) were published neither in English nor in German. Four additional articles reported veterinary cases. Out of the remaining 38 articles only 23 were based on studies focusing on colpocleisis or colpectomy and related surgical techniques or outcome measures. Some reports focused on clinical outcomes following partial Neugebauer-Le Fort colpocleisis, total colpocleisis or partial colpectomy [1-10]. These papers dealt mainly with objective or subjective cure rates after prolapse surgery. Only a few papers investigated postoperative SUI and bladder function. Glavind (2005) and Hoffman (2003) included 17 and 41 patients, respectively, with total colpectomies [11,12]. Total colpectomy was often synonymously used to total colpocleisis. To our understanding, while the first refers to a full oncologic excision of all vaginal and paravaginal tissues down to the vulva, the latter refers to a removal of the vaginal skin with surgical closure of the limbs of the levator ani muscle for prolapse surgery. So far, all reports focused on surgical techniques preserving the integrity of the suburethral tissue (usually the first $3 \mathrm{~cm}$ of the anterior vaginal wall), even when total colpectomy was performed for pelvic organ prolapse $[4,5,11,12]$. Some authors reported on combined prolapse and incontinence surgery, where up to $100 \%$ of their patients underwent concomitant midurethral sling placement at time of colpocleisis $[1,9,13,14]$. The incidence of de novo urinary incontinence - if at all quoted - varied between $0-27 \%[3,4,10,11]$. No report was dealing with the management of urinary incontinence following colpocleisis or radical oncologic colpectomy with the subsequent need of incontinence therapy. To the best of our knowledge, we here present the first case managing urinary incontinence following radical colpectomy.

\section{Case description}

A 67-year old abdominally hysterectomized virgin with a narrow vagina underwent laparoscopic pelvic lymphadenectomy and

Correspondence to: Tanja Huelder, Department of Obstetrics and Gynecology, Cantonal Hospital St. Gallen, Rorschacher Strasse 95, 9007 St. Gallen, Switzerland, Tel: +41-71-494 1876, Fax: +41-71-494 2884, E-mail: tanja.huelder@kssg.ch

Key words: Urinary incontinence, Colpectomy, Bulking agent, Polyacrylamide hydrogel, Duloxetine

Received: August 26, 2017; Accepted: October 03, 2017; Published: October 06, 2017 
laparoscopic radical colpectomy (Figure 1) down to the hymen for amelanotic malignant melanoma of the vagina FIGO stage II (pT3b pN0 (0/16) L1 R0). The urogenital hiatus was closed with single node sutures. Following removal of the transurethral urine catheter the patient, who was continent prior to surgery, complained about a SUI provoked by coughing, sneezing, laughing, lifting a weight and changing of position. Occasionally, the patient experienced nocturia as well as urgency with consecutive leakage of urine. Her cough test showed a distinct leakage of urine in horizontal as well as upright position. The urethra pressure profile confirmed a pathological depression quotient (Figure 2). All other urodynamic parameters were normal. Due to the fact that colpectomy was performed down to the level of the hymen and the urogenital hiatus was closed the suburethral area was not easily accessible for a midurethral sling. In addition, there was a lack of supportive tissue around the bladder neck for colposuspension. Thus, we decided to treat the SUI by transurethral injection of Polyacrylamide-Hydrogel (PAHG). The aim was to minimize the operative risk of this patient. The operation was performed as described by Lose in 2010 [15]. Three weeks after surgery the patient declared substantial improvement of the SUI, with only occasional leakage of urine. Her satisfaction score (Visual Analog scale, VAS) was by $8 / 10$. The remaining Mixed Urinary Incontinence (MUI) symptoms were treated with duloxetine $2 \times 20 \mathrm{mg}$ under which the patient reached continence and full satisfaction (VAS 10/10).

\section{Discussion}

There are several well-established options to treat SUI. Abdominal and vaginal colposuspensions require an intact paracolpic connective tissue, especially adjacent to the bladder neck. Midurethral sling

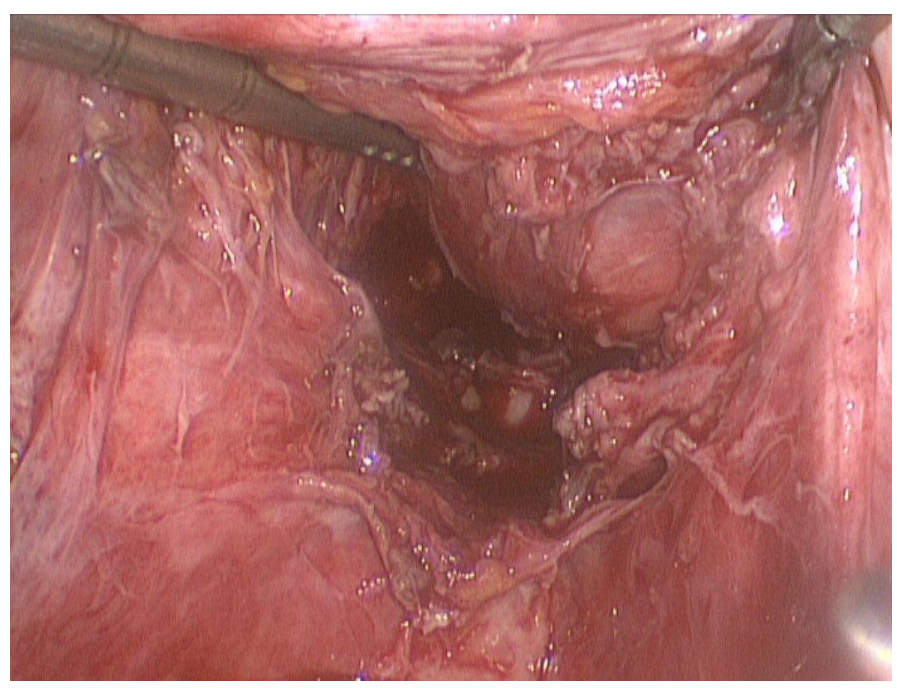

Figure 1. Laparoscopic view after total colpectomy

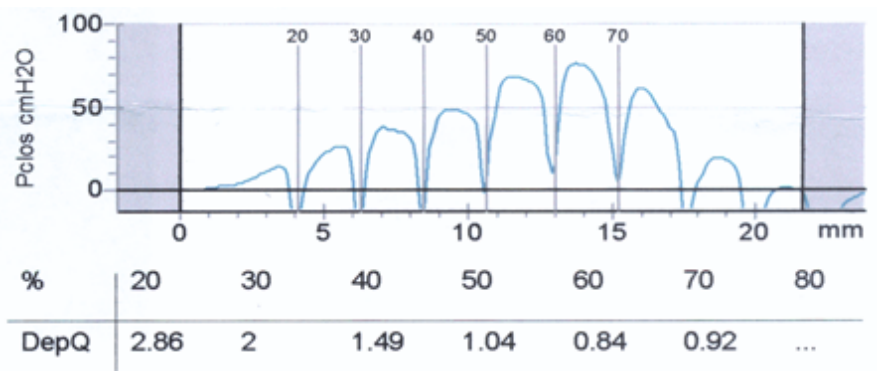

Figure 2. Pathological depression quotient in urethra pressure profile operations to suspend the urethra require a broadly normal suburethral space. However, in the present case not only the vaginal epithelium but the entire vaginal wall including the paracolpium was removed down to the level of the external urethral meatus. The hiatus urogenitalis was occluded and the skin was closed using the labia minora. Thus, neither classical colposuspension nor sling surgery was easily applicable. The literature review did not provide any recommendations for this particular situation. We decided to apply a bulking agent as an easily applicable alternative option to traditional sling or colposuspension surgery.

Ideally, a bulking agent is not immunologically effective; it is hypoallergenic, biocompatible and does not show biodegradation or migration [16]. In the past, substances like autologous fat, silicone, teflon, carbon, hyaluronic acid, collagen and other compounds were assessed for their capability to increase quality of life of patients suffering from SUI. However, most of these substances were little efficient (autologous fat) and/or led to complications. The following complications have been observed: Vascular diseases were associated with silicone migration, fibrosis and granuloma have been induced by teflon or hyaluronic acid, allergic reactions may have been caused by collagen, and even fat embolisms have been reported following instillation of bulking agents $[15,16]$. For quite some time PAHG, a hydrogel, is available on the market to treat SUI. PAHG is micro-particle free, biocompatible, stable, non-absorbable and non-allergenic. Healing rates of $4-83 \%$ and total response rates of $40-100 \%$, respectively, have been reported $[15,17]$. The study of Lose et al. showed that following suburethral injection of PAHG, urinary tract infection affected $7.4 \%$ and transient urinary retention affected $3 \%$ of women, while re-injection of PAHG was necessary in up to $35 \%$ [15].

Duloxetine in many countries is the only approved drug for the treatment of female SUI. SNRIs increase the bladder outlet resistance by contributing to the contraction of bladder neck/proximal urethra smooth muscle cells and respectively to an increased tonus of the striated sections of the urethral sphincter, resulting in a relief of SUI. The effect of the SNRI rather seems to be a central modulation (Onuf's nucleus of spinal cord) than a direct peripheral muscle stimulation [18]. Under medication of SNRIs, patients experience a significant reduction of incontinence episodes and an improvement in quality of life. Nevertheless, SNRIs seem to have a greater effect on women with MUI than on women with isolated SUI. Substantial dose-dependent side effects of the therapy are nausea (5.7-20.2\%), dizziness (1.6-3\%), dryness of the mouth (1.4-19.4\%), constipation (9.1-10.4\%), fatigue (1.2-14.2\%) and hyperhidrosis (3.3-5.2\%). Hereby, the difference between treatment and placebo group was not always significant $[19,20]$.

\section{Conclusion}

To the best of our knowledge, this is the first case reporting successful treatment of de novo urinary incontinence after radical oncologic colpectomy. Submucosal instillation of PAHG-bulking agent combined with duloxetine should be considered for patients with SUI following radical oncologic colpectomy.

\section{References}

1. Krissi H, Aviram A, Eitan R, From A, Wiznitzer A, et al. (2015) Risk factors for recurrence after Le Fort colpocleisis for severe pelvic organ prolapse in elderly women. Int J Surg 20: 75-79. [Crossref]

2. Goldman J, Ovadia J, Feldberg D (1981) The Neugebauer-Le Fort operation: a review of 118 partial colpocleises. Eur J Obstet Gynecol Reprod Biol 12: 31-35. [Crossref]

3. Hanson GE, Keettel WC (1969) The Neugebauer-Le Fort operation. A review of 288 colpocleises. Obstet Gynecol 34: 352-357. [Crossref] 
4. FitzGerald MP1, Brubaker L (2003) Colpocleisis and urinary incontinence. Am J Obstet Gynecol 189: 1241-1244. [Crossref]

5. Reisenauer C1, Oberlechner E, Schoenfisch B, Wallwiener D, Huebner M (2013) Modified LeFort colpocleisis: clinical outcome and patient satisfaction. Arch Gynecol Obstet 288: 1349-1353. [Crossref]

6. Vij M, Bombieri L, Dua A, Freeman R (2014) Long-term follow-up after colpocleisis: regret, bowel, and bladder function. Int Urogynecol $J$ 25: 811-815. [Crossref]

7. Fitzgerald MP, Richter HE, Bradley CS, Ye W, Visco AC, et al. (2008) Pelvic support, pelvic symptoms, and patient satisfaction after colpocleisis. Int Urogynecol $J$ Pelvic Floor Dysfunct 19: 1603-1609. [Crossref]

8. Harmanli OH1, Dandolu V, Chatwani AJ, Grody MT (2003) Total colpocleisis for severe pelvic organ prolapse. J Reprod Med 48: 703-706. [Crossref]

9. Koski ME, Chow D, Bedestani A, Togami JM, Chesson RR, et al. (2012) Colpocleisis for advanced pelvic organ prolapse. Urology 80: 542-546. [Crossref]

10. DeLancey JO, Morley GW (1997) Total colpocleisis for vaginal eversion. Am J Obstet Gynecol 176: 1228-1232. [Crossref]

11. Glavind K, Kempf L (2005) Colpectomy or Le Fort colpocleisis--a good option in selected elderly patients. Int Urogynecol J Pelvic Floor Dysfunct 16: 48-51. [Crossref]

12. Hoffman MS, Cardosi RJ, Lockhart J, Hall DC, Murphy SJ (2003) Vaginectomy with pelvic herniorrhaphy for prolapse. Am J Obstet Gynecol 189: 364-370. [Crossref]
13. Abbasy S, Lowenstein L, Pham T, Mueller ER, Kenton K, et al. (2009) Urinary retention is uncommon after colpocleisis with concomitant mid-urethral sling. Int Urogynecol $J$ Pelvic Floor Dysfunct 20: 213-216. [Crossref]

14. Smith AL, Karp DR, Lefevre R, Aguilar VC, Davila GW (2011) LeFort colpocleisis and stress incontinence: weighing the risk of voiding dysfunction with sling placement Int Urogynecol J 22: 1357-1362. [Crossref]

15. Lose G, Sorensen HC, Axelsen SM, Falconer C, Lobodasch K, et al. (2010) An open multicenter study of polyacrylamide hydrogel (Bulkamid(R)) for female stress and mixed urinary incontinence. Int Urogynecol J 21: 1471-1477. [Crossref]

16. Kerr LA (2005) Bulking agents in the treatment of stress urinary incontinence: history, outcomes, patient populations, and reimbursement profile. Reviews in urology 7 (Suppl 1): S3-S11. [Crossref]

17. Kotb AF, Campeau L, Corcos J (2009) Urethral bulking agents: techniques and outcomes. Curr Urol Rep 10: 396-400. [Crossref]

18. Basu M, Duckett JR (2009) Update on duloxetine for the management of stress urinary incontinence. Clin Interv Aging 4: 25-30 [Crossref]

19. Cardozo L, Lange R, Voss S, Beardsworth A, Manning M, et al (2010) Short- and long-term efficacy and safety of duloxetine in women with predominant stress urinary incontinence. Curr Med Res Opin 26: 253-261. [Crossref]

20. Mariappan P, Alhasso A, Ballantyne Z, Ballantyne Z, Grant A, N'Dow J (2007) Duloxetine, a serotonin and noradrenaline reuptake inhibitor (SNRI) for the treatment of stress urinary incontinence: a systematic review. Eur Urol 51: 67-74. [Crossref]

Copyright: $(02017$ Huelder T. This is an open-access article distributed under the terms of the Creative Commons Attribution License, which permits unrestricted use, distribution, and reproduction in any medium, provided the original author and source are credited. 